\title{
PEMODELAN TUTUPAN LAHAN UNTUK MENJAMIN KEBERLANJUTAN DEBIT SUNGAI (SUATU STUDI DI SUB DAS CIKAPUNDUNG-MARIBAYA)
}

\author{
Aditya Dwifebri Christian Wibowo', Mahawan Karuniasa², \\ Dwita Sutjiningsih ${ }^{3}$

\footnotetext{
${ }^{1}$ Sekolah Ilmu Lingkungan, Pascasarjana Universitas Indonesia

${ }^{2}$ Sekolah Ilmu Lingkungan, Pascasarjana Universitas Indonesia
} \\ ${ }^{3}$ Sekolah Ilmu Lingkungan, Pascasarjana Universitas Indonesia \\ Email: adityadwifebri@gmail.com
}

\begin{abstract}
Changes in land use in the Cikapundung watershed, ie changes in forest land to builtup land, have an impact on the quantity of river water. Changes in land use in the Cikapundung River catchment are not ideal conditions for absorbing water. If land conversion is not controlled, it can have a large impact on reducing the availability of water resources for subordinate areas or what is called water scarcity. Analysis that takes into account land use and discharge can be done with several hydrological analysis methods, one of them is the Soil Conservation Service Curve Number (SCSCN) method. Based on the calculation, the CN value was changed in 2014 from 57.275 to 62.591 where land cover changes began to occur.
\end{abstract}

Keywords: land use, river water, water scarcity, hydrology, CN value

\begin{abstract}
ABSTRAK
Perubahan penggunaan lahan di DAS Cikapundung, yaitu perubahan lahan hutan menjadi lahan terbangun, berdampak pada kuantitas air sungai. Perubahan penggunaan lahan di DAS Sungai Cikapundung bukanlah kondisi ideal untuk menyerap air. Jika konversi lahan tidak dikontrol, hal ini dapat berdampak besar pada pengurangan ketersediaan sumber daya air untuk daerah bawahan atau apa yang disebut kelangkaan air. Analisis yang memperhitungkan penggunaan dan pembuangan lahan dapat dilakukan dengan beberapa metode analisis hidrologi, salah satunya adalah metode Nomor Kurva Layanan Konservasi Tanah (SCS-CN). Berdasarkan perhitungan, nilai CN diubah pada 2014 dari 57.275 menjadi 62.591 di mana perubahan tutupan lahan mulai terjadi.
\end{abstract}

Kata kunci: guna lahan, air sungai, kelangkaan air, hidrologi, nilai $C N$ 


\section{PENDAHULUAN}

Salah satu sumber air permukaan terbesar untuk Kota Bandung yaitu Sungai Cikapundung, di mana sungai ini melintasi Kota Bandung sepanjang 15,50 km dengan 10,57 km yang penggunaan lahan di antaranya adalah daerah permukiman padat yang dipenuhi bangunan dan selebihnya adalah daerah perdagangan dan lain-lain yang memanfaatkan fungsi sungai tersebut, umumnya, tanpa memperhatikan kelestarian lingkungan (Bachrein, 2012). Sungai Cikapundung berada dalam kawasan Daerah Aliran Sungai (DAS) Cikapundung yang merupakan kawasan padat penduduk dan pusat perekonomian, serta kawasan wisata (Marbun, 2018).

PDAM Tirta Wening Kota Bandung, pada tahun 2003, baru dapat menyediakan air sebesar 1.183 liter/detik atau 54 persen, sedangkan penduduk sisanya masih menggunakan sistem individu (membuat sumur) dan dari hasil pembuatan sumur bor, baik berupa sumur uji maupun sumur produksi terdapat potensi air tanah tertekan dengan debit sekitar 5-15 liter/detik dan di beberapa wilayah ada yang mampu mencapai 20 liter/detik (Ramelan, 2004). Penarikan air tanah lokal lainnya yang terjadi di beberapa titik di DAS Cikapundung disebabkan kemungkinan oleh pemompaan air dari sumur dalam yang dimiliki oleh hotelhotel kecil dan bisnis akomodasi (Darul et al., 2016). Kota Bandung memiliki nilai indeks kekritisan air tanah lebih dari 100\% yaitu sebesar 158,52\% sehingga Kota Bandung masuk kedalam kategori sangat kritis padahal pertumbuhan populasi dan perkembangan ekonomi di Wilayah Bandung Raya sangat tinggi dan seharusnya didukung oleh sistem pasokan air yang andal dan sistem pencegahan banjir (Kuntoro et al., 2017; Marbun, 2018).

Perubahan tata guna lahan di DAS Cikapundung, yaitu perubahan lahan hutan menjadi lahan terbangun, memberikan dampak pada kuantitas air sungai yaitu infiltrasi tanah yang sangat minim dan berakibat pada tidak adanya air tanah yang menyebabkan berkurangnya aliran dasar (baseflow) sungai pada musim kering (Sofyan, 2004). Perubahan tata guna lahan di daerah tangkapan Sungai Cikapundung menjadi kondisi yang tidak ideal untuk meresapkan air, menurut Maria (2008), akan meningkatkan nilai koefisien runoff sehingga jumlah air yang meresap semakin berkurang. Potensi DAS Cikapundung pada kondisi normal dapat mencapai 152,32 juta m3/tahun, tetapi pada saat musim kering atau kondisi minimum hanya mampu memberikan kontribusi sekitar 21,13 juta m3/tahun (Sabar, 2006). Berdasarkan kondisi tersebut, debit pada kondisi normal dapat memenuhi kebutuhan air bersih penduduk Kota 
Bandung, namun pada kondisi minimum tidak dapat memenuhi kebutuhan air bersih penduduk Kota Bandung. Kondisi tersebut juga memperlihatkan bahwa perlu dilakukan peningkatan kapasitas produksi air bersih di PDAM Tirta Wening dalam jumlah yang sangat besar. Namun peningkatan kapasitas produksi di PDAM Tirta Wening Kota Bandung juga memerlukan kondisi debit sungai yang stabil.

Kondisi ini menyebabkan masyarakat baik yang menjadi pelanggan maupun yang tidak menjadi PDAM Tirta Wening Kota Bandung kesulitan mendapatkan air bersih ketika musim kering. Masyarakat Kota Bandung yang bukan pelanggan PDAM Tirta Wening Kota Bandung, seperti sebagian masyarakat di Kelurahan Tamansari misalnya, memanfaatkan air tanah dan sumber mata air secara langsung sebagai sumber air bersih untuk memenuhi kebutuhan sehari-hari. Alasan sebagian masyarakat di Kelurahan Tamansari masih menggantungkan pada sumber air tanah dan mata air selain karena mudah didapatkan juga lebih murah biayanya (Raksanagara et al., 2017). Selain itu, terdapat kondisi lainnya di mana kebutuhan air bersih yang digunakan oleh hotel dan obyek daya tarik wisata di Kota Bandung diperkirakan akan meningkat setiap tahunnya sehingga membuat gap jumlah air bersih yang didistribusikan ke masyarakat akan semakin besar. Jika alih fungsi lahan tidak dikendalikan maka dapat menimbulkan dampak yang besar pada berkurangnya ketersediaan sumber daya air bagi kawasan bawahannya atau yang disebut dengan kelangkaan air. Selain itu, alih fungsi lahan juga dapat berdampak pada sosial ekonomi masyarakat antara lain perubahan mata pencaharian dan pendapatan (Ante et al., 2016).

Potensi kelangkaan air dan dampak sosial ekonomi masyarakat akibat dari alih fungsi lahan di DAS Cikapundung, khususnya di bagian hulu yaitu Sub DAS Cikapundung-Maribaya dapat diminimalkan melalui optimasi tata guna lahan. Analisis yang memperhitungkan guna lahan dan debit dapat dilakukan dengan beberapa metode analisis hidrologi, salah satunysa metode Soil Conservation Service Curve Number (SCS-CN). Penelitian ini akan menghitung besarnya nilai CN untuk masing-masing tutupan lahan di Sub DAS Cikapundung-Maribaya agar dapat digunakan untuk analisis lebih lanjut terkait optimasi guna lahan. 


\section{METODOLOGI PENELITIAN}

Lokasi penelitian berada di Sub DAS Cikapundung-Maribaya yang berada di hulu DAS Cikapundung. Penelitian ini menggunakan pendekatan kuantitatif dengan metode analisis kuantitatif. Metode kuantitatif yang digunakan adalah metode SCS-CN dengan menggunakan rumus sebagai berikut:

$$
\begin{aligned}
& Q=\frac{\left(P-I_{a}\right)^{2}}{\left(P-I_{a}\right)+S} \ldots \\
& I_{a}=0,2 S \ldots \ldots \ldots \\
& S=\frac{1000}{C N}-10
\end{aligned}
$$

dengan:

$\mathrm{Q} \quad=$ tinggi aliran (in)

$\mathrm{P} \quad=$ curah hujan (in)

$\mathrm{S} \quad=$ retensi maksimum (in)

Ia = initial abstraction (in)

Setelah dihitung nilai CN, perlu dihitung nilai NSE dari debit yang dihasilkan dengan menggunakan CN tersebut. Jika nilai Nash-Sutcliffe Efficiency (NSE)di bawah 36\%, maka data tidak memenuhi. Adapun nilai NSE dihitung menggunakan rumus:

$$
N S E=1-\frac{\sum_{t=1}^{T}\left(Q_{m}^{t}-Q_{o}^{t}\right)^{2}}{\sum_{t=1}^{T}\left(Q_{m}^{t}-\overline{Q_{o}}\right)^{2}}
$$

dengan:

Qo = debit hasil pengukuran $\left(\mathrm{m}^{3} / \mathrm{dtk}\right)$

Qm = debit hasil perhitungan $\left(\mathrm{m}^{3} / \mathrm{dtk}\right)$

$Q_{o}^{t} \quad=$ debit hasil pengukuran pada waktu $\mathrm{t}\left(\mathrm{m}^{3} / \mathrm{dtk}\right)$

$Q_{m}^{t} \quad=$ debit hasil perhitungan pada waktu $\mathrm{t}\left(\mathrm{m}^{3} / \mathrm{dtk}\right)$

Sumber: Fadhli et al., 2015

Tabel 1.1 Interpretasi NSE

\begin{tabular}{|c|c|}
\hline Nilai NSE & Interpretasi \\
\hline NSE $>0,75$ & Baik \\
\hline $0,36<$ NSE $<0,75$ & Memenuhi \\
\hline NSE $<0,36$ & Tidak Memenuhi \\
\hline
\end{tabular}




\section{HASIL DAN PEMBAHASAN}

Perubahan guna lahan di Sub DAS Cikapundung-Maribaya sebagaimana telah dijelaskan pada bagian sebelumnya berdampak pada kondisi debit sungai. Namun, diperlukan analisis lebih lanjut mengenai perubahan guna lahan yang terjadi di sub DAS CikapundungMaribaya pada debit Sungai Cikapundung yang menjadi sungai utama pada sub DAS tersebut. Bagian ini akan menganalisis pengaruh perubahan guna lahan di Sub DAS CikapundungMaribaya pada debit Sungai Cikapundung yang menjadi salah satu sumber air baku Kota Bandung. Analisis yang dilakukan sebagai berikut:

1. Perhitungan curah hujan DAS dengan Poligon Thiessen

2. Regresi linear antara curah hujan dan debit

\section{Analisis SCS-CN method}

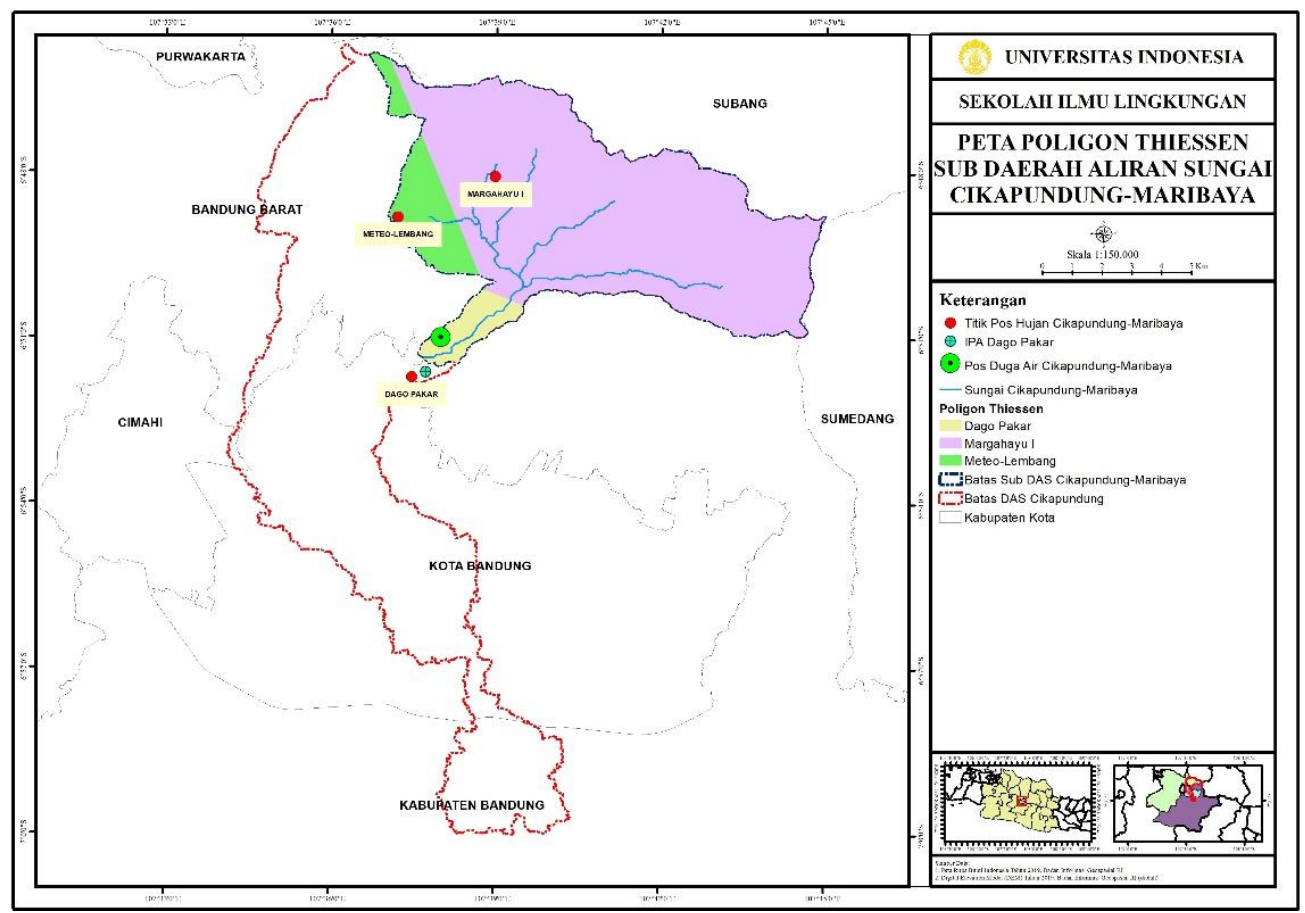

Gambar 1.1 Peta Poligon Thiessen dengan 3 (tiga) Stasiun Hujan Sumber: Badan Informasi Geospasial, 2020, telah diolah kembali

Penghitungan curah hujan dengan Poligon Thiessen dilakukan dengan bantuan perangkat lunak Arc-GIS 4.0. Poligon Thiessen di Sub DAS Cikapundung-Maribaya menggunakan 3 (tiga) stasiun pengamatan hujan yaitu Dago Pakar, Meteo-Lembang, dan Margahayu I sebagaimana dapat dilihat pada Gambar 1.1. Berdasarkan hasil analisis, 
diperoleh poligon Margahayu I seluas 6.758,92 ha, Meteo-Lembang poligon 779,65 ha, dan poligon Dago Pakar seluas 377,61 ha. Luas masing-masing poligon dibandingkan dengan luas Sub DAS Cikapundung-Maribaya untuk memperoleh bobot masing-masing stasiun. Setelah dihitung, diperoleh bobot masing-masing stasiun yaitu Dago Pakar 0,05, Meteo-Lembang 0,10, dan Margahayu I 0,85 sebagai faktor pengali dari curah hujan masing-masing stasiun. Namun, tidak setiap tahun data-data di ketiga stasiun tersebut lengkap. Oleh karena itu, perlu dilakukan perhitungan untuk melengkapi data hujan yang hilang.

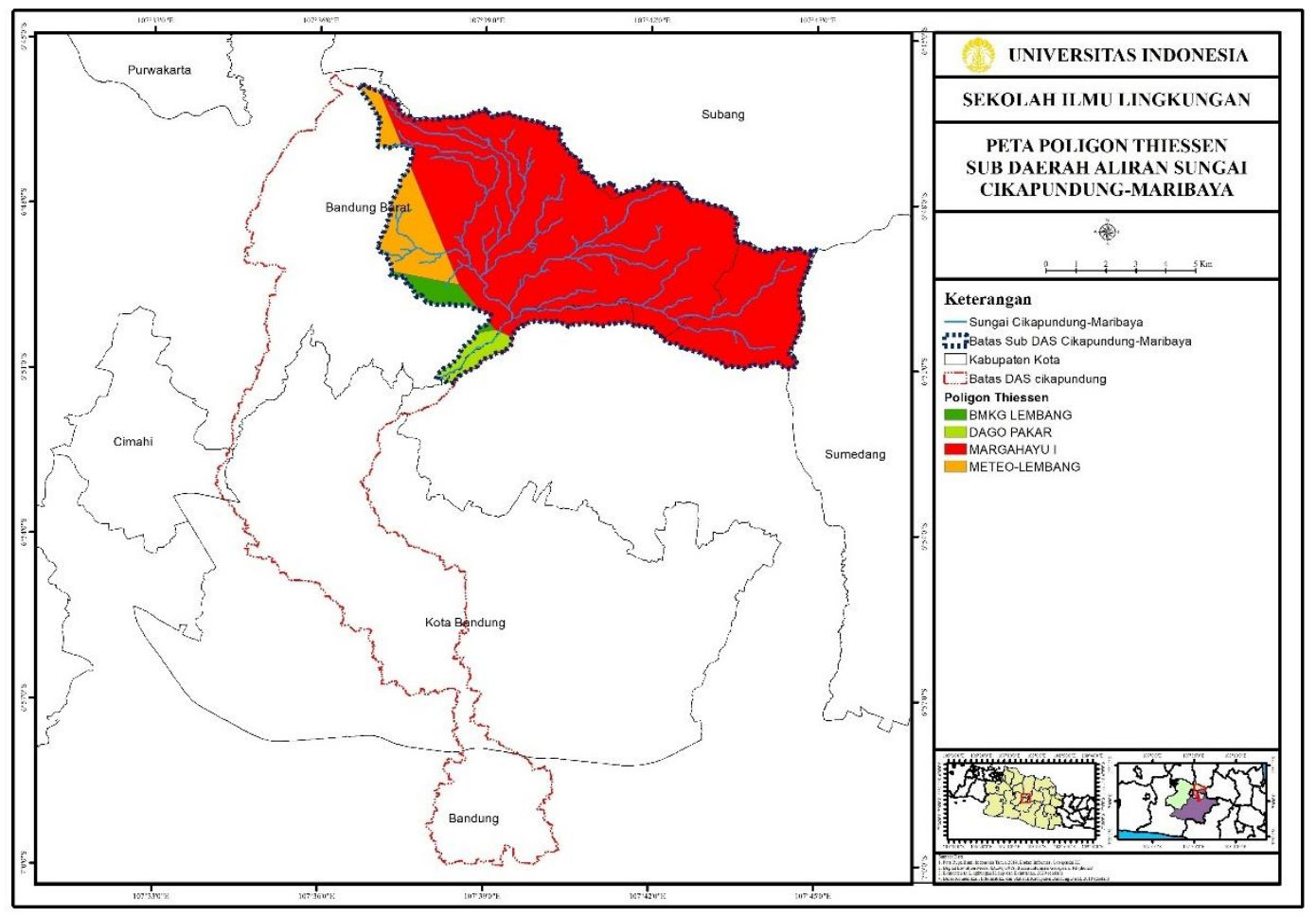

Gambar 1.2 Poligon Thiessen Sub DAS Cikapundung-Maribaya dengan 4 Stasiun Hujan

Penghitungan data hujan hilang dilakukan dengan minimal 2 (dua) stasiun di sekitarnya memiliki data yang lengkap. Namun, pada tahun 2006 dan 2011 dari 3 (tiga) stasiun yaitu Dago Pakar, Meteo-Lembang, dan Margahayu I, hanya Stasiun Dago Pakar yang memiliki data hujan lengkap. Oleh karena itu, penghitungan juga dilakukan dengan menggunakan data pada stasiun terdekat lainnya yang lengkap yaitu Stasiun BMKG Lembang. Penambahan stasiun hujan dalam perhitungan data hujan tentu akan mempengaruhi bobot yang dihasilkan dari metode analisis Poligon Thiessen untuk menghitung besarnya hujan daerah di Sub DAS 
Cikapundung-Maribaya. Poligon Thiessen yang semula hanya menggunakan 3 (tiga) stasiun hujan dihitung kembali dengan menggunakan 4 (empat) stasiun hujan sehingga menjadi seperti pada Gambar 1.2. Berdasarkan analisis Poligon Thiessen dengan 4 (empat) stasiun hujan, diperoleh bobot masing-masing stasiun yaitu Dago Pakar 0,04, Meteo-Lembang 0,08, Margahayu I 0,85, dan BKMG Lembang 0,03 sebagai faktor pengali dari curah hujan masingmasing stasiun. Data hujan tahunan di masing-masing stasiun sebagaimana dapat dilihat pada Tabel 1.3 dikalikan dengan bobot masing-masing stasiun tersebut berdasarkan analisis Poligon Thiessen lalu dijumlahkan untuk memperoleh hujan Sub DAS Cikapundung-Maribaya sebagaimana dapat dilihat pada Tabel 1.3. Untuk tahun 2004, 2009, dan 2014-2018 hanya Stasiun BMKG Lembang yang memiliki data hujan yang lengkap, maka data curah hujan yang digunakan untuk tahun 2004, 2009, dan 2014-2018 adalah data curah hujan yang bersumber dari Stasiun BMKG Lembang yang diperoleh dari BMKG Pusat.

Tabel 1.2 Curah Hujan Stasiun Dagor Pakar, Margahayu, Meteo-Lembang, dan BMKG Lembang

\begin{tabular}{|c|c|c|c|c|c|}
\hline Tahun & Dago Pakar & Margahayu & Meteo-Lembang & $\begin{array}{c}\text { BMKG } \\
\text { Lembang }\end{array}$ & Total (mm/tahun) \\
\hline 2004 & - & - & - & $1.652,60$ & $1.652,60$ \\
\hline 2005 & 938,51 & $1.984,00$ & $2.322,00$ & - & $5.244,51$ \\
\hline 2006 & $1.465,00$ & $2.053,18$ & $1.261,22$ & $1.374,80$ & $6.154,19$ \\
\hline 2007 & $1.978,21$ & $2.999,00$ & $2.153,00$ & $2.113,10$ & $9.243,31$ \\
\hline 2008 & $1.417,00$ & $3.424,76$ & $1.341,00$ & $1.725,90$ & $7.908,66$ \\
\hline 2009 & - & - & - & $1.905,00$ & $1.905,00$ \\
\hline 2010 & $3.958,00$ & $3.301,00$ & $2.846,00$ & $3.481,00$ & $13.586,00$ \\
\hline 2011 & $1.310,00$ & $1.022,22$ & $1.553,79$ & $1.608,90$ & $5.494,92$ \\
\hline 2012 & $1.530,00$ & $2.293,50$ & $2.590,00$ & $1.836,60$ & $8.250,10$ \\
\hline 2013 & $2.143,00$ & $2.533,50$ & $2.002,50$ & $2.039,20$ & $8.718,20$ \\
\hline 2014 & - & - & - & $1.865,94$ & $1.865,94$ \\
\hline 2015 & - & - & - & $1.958,90$ & $1.958,90$ \\
\hline 2016 & - & - & - & $2.674,10$ & $2.674,10$ \\
\hline 2017 & - & - & - & $1.843,00$ & $1.843,00$ \\
\hline 2018 & - & - & - & $1.815,04$ & $1.815,04$ \\
\hline
\end{tabular}

Sumber: BBWS Citarum, 2020, telah diolah kembali 
Setelah diperoleh data hujan Sub DAS Cikapundung-Maribaya tahun 2004-2018, maka selanjutnya dilakukan uji ketiadaan tren pada data hujan tersebut. Uji ketiadaan tren diperlukan karena apabila dalam suatu deret berkala menunjukkan adanya tren, maka data tersebut tidak disarankan untuk digunakan. Uji ketiadaan tren yang digunakan pada penelitian ini adalah uji korelasi peringkat Metode Spearman. Berdasarkan hasil perhitungan Metode Spearman pada hujan Sub DAS Cikapundung-Maribaya dengan menggunakan derajat kebebasan $\mathrm{dk}=\mathrm{n}-2=$ 13, dengan $\alpha=5 \%$, diperoleh t Tabel (tc) $=1,761$ (dari tabel nilai kritis pada distribusi-t uji dua sisi). Nilai t hitung adalah 0,61 atau lebih kecil dari $\mathrm{t}$ Tabel $(\mathrm{t}<\mathrm{tc})$ sebagaimana dapat dilihat pada Tabel 1.4. Artinya, pengujian menunjukan ketiadaan tren (independen) pada data curah hujan sehingga data dapat diterima

Tabel 1.3 Curah Hujan Sub DAS Cikapundung-Maribaya

\begin{tabular}{|c|c|c|c|c|c|}
\hline Tahun* & $\begin{array}{c}\text { Dago Pakar } \\
(0,04)\end{array}$ & $\begin{array}{c}\text { Margahayu } \\
(0,85)\end{array}$ & $\begin{array}{c}\text { Meteo-Lembang } \\
(0,08)\end{array}$ & $\begin{array}{c}\text { BMKG } \\
\text { Lembang } \\
(0,03)\end{array}$ & $\begin{array}{c}\text { Total } \\
\text { (mm/tahun) }\end{array}$ \\
\hline 2004 & & & & $1.652,60$ & $1.652,60$ \\
\hline 2005 & 469,26 & $1.686,40$ & 232,20 & & $2.387,86$ \\
\hline 2006 & 64,26 & $1.746,70$ & 101,99 & 33,74 & $1.946,69$ \\
\hline 2007 & 86,77 & $2.551,34$ & 174,10 & 51,87 & $2.864,07$ \\
\hline 2008 & 62,15 & $2.913,55$ & 108,44 & 42,36 & $3.126,50$ \\
\hline 2009 & & & & $1.905,00$ & $1.905,00$ \\
\hline 2010 & 173,60 & $2.808,26$ & 230,14 & 85,44 & $3.297,44$ \\
\hline 2011 & 57,46 & 869,64 & 125,64 & 39,49 & $1.092,23$ \\
\hline 2012 & 67,11 & $1.951,15$ & 209,44 & 45,08 & $2.272,77$ \\
\hline 2013 & 93,99 & $2.155,33$ & 161,93 & 50,05 & $2.461,30$ \\
\hline 2014 & & & & $1.865,94$ & $1.865,94$ \\
\hline 2015 & & & & $1.958,90$ & $1.958,90$ \\
\hline 2016 & & & & $2.674,10$ & $2.674,10$ \\
\hline 2017 & & & & $1.843,00$ & $1.843,00$ \\
\hline 2018 & & & & $1.815,04$ & $1.815,04$ \\
\hline
\end{tabular}

Sumber: BBWS Citarum, 2020, telah diolah kembali

*Tahun 2005 menggunakan bobot Poligon Thiessen dengan 3 (tiga) stasiun hujan (Gambar 1.1) 


\section{IJEEM: Indonesian Journal of Environmental Education and Management e-ISSN: 2549-5798 \\ Vol.6 No. 2, 31 Juli 2021 \\ DOI : doi.org/10.21009/IJEEM.062.01}

Curah hujan adalah salah satu variabel yang mempengaruhi debit sungai. Data debit yang digunakan dalam penelitian ini adalah data debit Sungai Cikapundung-Maribaya yang diperoleh dari Balai Besar Wilayah Sungai (BBWS) Citarum. Data debit rerata tahunan yang tersedia adalah tahun 2004-2014, sedangkan periode waktu yang digunakan dalam penelitian ini adalah tahun 2009-2018. Oleh karena itu, untuk menghitung debit tahun 2015-2018 dilakukan dengan cara meregresikan data debit dengan data curah hujan tahunan 2004-2014 yang dapat dilihat pada Tabel 1.5 sehingga dapat diperoleh rumus regresi untuk menghitung debit tahun 2015-2018.

Tabel 1.4 Perhitungan Metode Spearman pada Hujan Sub DAS Cikapundung-Maribaya

\begin{tabular}{|c|c|c|c|c|c|c|c|}
\hline No. & Tahun & Curah Hujan (mm/tahun) & Tahun & $\mathrm{CH}$ & $\mathrm{Rt}$ & $\mathrm{dt}$ & $\mathrm{dt} 2$ \\
\hline 1 & 2004 & 1652,60 & 2010 & 3297,44 & 7 & 6 & 36 \\
\hline 2 & 2005 & 1965,53 & 2008 & 3126,50 & 5 & 3 & 9 \\
\hline 3 & 2006 & 1946,69 & 2007 & 2864,07 & 4 & 1 & 1 \\
\hline 4 & 2007 & 2864,07 & 2016 & 2674,10 & 13 & 9 & 81 \\
\hline 5 & 2008 & 3126,50 & 2013 & 2461,30 & 10 & 5 & 25 \\
\hline 6 & 2009 & 1905,00 & 2012 & 2272,77 & 9 & 3 & 9 \\
\hline 7 & 2010 & 3297,44 & 2005 & 1965,53 & 2 & -5 & 25 \\
\hline 8 & 2011 & 1092,23 & 2015 & 1958,90 & 12 & 4 & 16 \\
\hline 9 & 2012 & 2272,77 & 2006 & 1946,69 & 3 & -6 & 36 \\
\hline 10 & 2013 & 2461,30 & 2009 & 1905,00 & 6 & -4 & 16 \\
\hline 11 & 2014 & 1865,94 & 2014 & 1865,94 & 11 & 0 & 0 \\
\hline 12 & 2015 & 1958,90 & 2017 & 1843,00 & 14 & 2 & 4 \\
\hline 13 & 2016 & 2674,10 & 2018 & 1815,04 & 15 & 2 & 4 \\
\hline 14 & 2017 & 1843,00 & 2004 & 1652,60 & 1 & -13 & 169 \\
\hline 15 & 2018 & 1815,04 & 2011 & 1092,23 & 8 & -7 & 49 \\
\hline \multicolumn{7}{|c|}{ Jumlah } & 480 \\
\hline \multicolumn{7}{|c|}{$\mathrm{n}$} & 15 \\
\hline \multicolumn{7}{|c|}{$\mathrm{Kp}$} & 0,14 \\
\hline \multicolumn{7}{|c|}{$\mathrm{t}$} & 0,52 \\
\hline \multicolumn{7}{|c|}{$\mathrm{dk}(5 \%)$} & 13 \\
\hline \multicolumn{7}{|c|}{ tc } & 1,76 \\
\hline
\end{tabular}

Sumber: BBWS Citarum, 2020, telah diolah kembali

*Curah hujan tahun 2004, 2009, dan 2014-2018 menggunakan data BPS Kota Bandung yang bersumber dari BMKG Lembang 
Tabel 1.5 Curah Hujan dan Debit Tahun 2004-2014

\begin{tabular}{|c|c|c|}
\hline Tahun & Curah Hujan (m/tahun) & Debit (m3/dtk) \\
\hline 2004 & $1,65^{*}$ & 3,26 \\
\hline 2005 & $1,97^{* *}$ & 3,49 \\
\hline 2006 & 1,95 & 2,37 \\
\hline 2007 & 2,86 & 3,41 \\
\hline 2008 & 3,13 & 3,54 \\
\hline 2009 & 1,91 & 3,22 \\
\hline 2010 & 3,30 & 5,49 \\
\hline 2011 & 1,09 & 1,87 \\
\hline 2012 & 2,27 & 1,94 \\
\hline 2013 & 2,46 & 2,37 \\
\hline 2014 & $1,87^{*}$ & 3,56 \\
\hline
\end{tabular}

Sumber: BBWS Citarum dan BMKG, 2020, telah diolah kembali

* Data Hujan diambil dari STA BMKG Lembang

** Data hujan dihitung menggunakan bobot Poligon Thiessen dengan 3 STA (Dago Pakar, Margahayu, dan Meteo-Lembang)

Regresi antara variabel debit dan curah hujan selanjutnya dianalisis dengan menggunakan bantuan perangkat lunak Statistical Package for the Social Sciences (SPSS) untuk memperkuat hasil analisis dengan melihat nilai signifikansi dan derajat kebebasan (degree of freedom). Beberapa pengujian yang dilakukan yaitu:

1. Uji korelasi dengan Bivariate Pearson

2. Uji distribusi normal

3. Uji autokorelasi

4. Uji heteroskedastisitas 
Tabel 1.6 Hasil Uji Korelasi Pearson

\begin{tabular}{|cc|c|}
\hline & & Debit Sungai \\
\cline { 2 - 4 } & $\begin{array}{c}\text { Pearson Hujan } \\
\text { Correlation } \\
\text { Sig. (2-tailed) }\end{array}$ & $.613^{*}$ \\
$\mathrm{~N}$ & .045 \\
& 11 \\
\hline
\end{tabular}

Sumber: Hasil perhitungan, 2020

Berdasarkan perhitungan dalam SPSS, diperoleh hasil masing-masing uji sebagaimana dapat dilihat pada Tabel 1.6, Tabel 1.7, Tabel 1.8, dan Tabel 1.9. Pengujian dilakukan untuk menentukan apakah variabel-variabel yang diuji dapat dilanjutkan untuk dilakukan analisis regresi linear atau tidak. Hasil uji korelasi menunjukkan bahwa nilai Pearson Correlation antara debit dengan curah hujan sebesar 0, dengan nilai signifikansi 0,045 atau lebih kecil dari 0,05. Artinya, berdasarkan hasil uji korelasi dapat disimpulkan bahwa terdapat pengaruh curah hujan pada debit. Hasil uji distribusi normal dilakukan dengan uji non parametriks (nonparameter test) Kolmogorov-Smirnof menunjukkan bahwa nilai signifikansi lebih besar dari 0,05. Artinya, berdasarkan hasil uji distribusi normal dapat disimpulkan bahwa data-data yang terdapat di setiap variabel terdistribusi normal.

Tabel 1.7 Hasil Uji Distribusi Normal

\begin{tabular}{|ll|c|}
\hline & & $\begin{array}{c}\text { Unstandardized } \\
\text { Residual }\end{array}$ \\
\hline $\mathrm{N}$ & Mean & 11 \\
Normal Parameters a,b & .0000000 \\
& Std. & .80191766 \\
& Deviation & .145 \\
Most Extreme Differences & Absolute & .145 \\
& Positive & -.134 \\
Test Statistic & Negative & .145 \\
Asymp. Sig. (2-tailed) & & $.200 \mathrm{c}, \mathrm{d}$ \\
\hline
\end{tabular}

a. Test distribution is Normal.

b. Calculated from data.

c. Lilliefors Significance Correction.

$\mathrm{d}$. This is a lower bound of the true significance.

Sumber: Hasil perhitungan, 202 
IJEEM: Indonesian Journal of Environmental Education and Management

e-ISSN: 2549-5798

Vol.6 No. 2, 31 Juli 2021

DOI : doi.org/10.21009/IJEEM.062.01

Tabel 1.8 Hasil Uji Autokorelasi

\begin{tabular}{|c|c|c|c|c|c|}
\hline Model & $\mathrm{R}$ & $\mathrm{R}$ Square & $\begin{array}{c}\text { Adjusted R } \\
\text { Square }\end{array}$ & $\begin{array}{c}\text { Std. Error of } \\
\text { the Estimate }\end{array}$ & $\begin{array}{c}\text { Durbin- } \\
\text { Watson }\end{array}$ \\
\hline 1 & $.613 \mathrm{a}$ & .376 & .306 & .84530 & 1.470 \\
\hline
\end{tabular}

a. Predictors: (Constant), Curah Hujan

b. Dependent Variable: Debit Sungai

Sumber: Hasil perhitungan, 2020

Hasil uji autokorelasi menunjukkan bahwa nilai Durbin-Watson sebesar 1,47 lebih besar dari batas atas (dU) yakni 1,32 dan kurang dari (4-dU) 4-1,32 = 2,68. Artinya, berdasarkan hasil uji korelasi pada variabel curah hujan dan debit dapat disimpulkan bahwa tidak terdapat gejala autokorelasi. Hasil uji heteroskedastisitas dilakukan menghitung residu dari regresi linear antara variabel curah hujan dengan variabel, kemudian residu tersebut diregresikan dengan variabel bebas yaitu curah hujan. Hasilnya menunjukkan bahwa nilai signifikansi dari setiap variabel lebih besar dari 0,05. Artinya, berdasarkan hasil uji heteroskedastisitas dapat disimpulkan bahwa tidak terdapat heteroskedastisitas pada variabel yang diuji.

Setelah dilakukan 4 (empat) pengujian pada variabel curah hujan dan debit, dapat disimpulkan bahwa dapat dilakukan analisis regresi linear berganda pada kedua variabel tersebut. Hasilnya adalah nilai signfikansi sebesar 0,045 atau lebih kecil dari 0,05 yang dapat dilihat pada Tabel 1.10. Artinya, variabel curah hujan berpengaruh pada variabel debit. Selanjutnya diperoleh rumus regresi linear sebagai berikut:

$$
Y=0,935 X+1,057
$$

dengan:

$$
\begin{array}{ll}
\mathrm{X} & =\text { curah hujan (m/tahun) } \\
\mathrm{Y} & =\operatorname{debit}\left(\mathrm{m}^{3} / \mathrm{dtk}\right)
\end{array}
$$


IJEEM: Indonesian Journal of Environmental Education and Management e-ISSN: 2549-5798

Vol.6 No. 2, 31 Juli 2021

DOI : doi.org/10.21009/IJEEM.062.01

Tabel 1.9 Hasil Uji Heteroskedastisitas

\begin{tabular}{|c|c|c|c|c|c|c|}
\hline & \multirow[b]{2}{*}{ Model } & \multicolumn{2}{|c|}{ Unstandardized Coefficients } & \multirow{2}{*}{$\begin{array}{l}\text { Standardized } \\
\text { Coefficients } \\
\text { Beta }\end{array}$} & \multirow[b]{2}{*}{$\mathrm{t}$} & \multirow[b]{2}{*}{ Sig. } \\
\hline & & $\mathrm{B}$ & Std. Error & & & \\
\hline \multirow[t]{2}{*}{1} & (Constant) & $4.441 \mathrm{E}-16$ & .930 & & .000 & 1.000 \\
\hline & Curah Hujan & .000 & .402 & .000 & .000 & 1.000 \\
\hline
\end{tabular}

a. Dependent Variable: Unstandardized Residual

Tabel 1.10 Hasil Regresi Linear

\begin{tabular}{|c|c|c|c|c|c|c|}
\hline & \multirow[b]{2}{*}{ Model } & \multicolumn{2}{|c|}{ Unstandardized Coefficients } & \multirow{2}{*}{$\begin{array}{c}\text { Standardized } \\
\text { Coefficients }\end{array}$} & \multirow[b]{2}{*}{$\mathrm{t}$} & \multirow[b]{2}{*}{ Sig. } \\
\hline & & B & Std. Error & & & \\
\hline \multirow[t]{2}{*}{1} & (Constant) & 1.057 & .930 & & 1.137 & .285 \\
\hline & Curah Hujan & .935 & .402 & .613 & 2.327 & .045 \\
\hline
\end{tabular}

a. Dependent Variable: Debit Sungai 


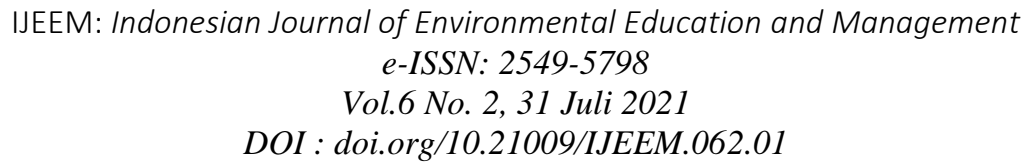

Tabel 1.11 Debit Tahun 2015-2018

\begin{tabular}{|c|c|c|}
\hline Tahun & $\begin{array}{c}\text { Curah Hujan } \\
\text { (m/tahun)* }\end{array}$ & Debit (m3/dtk) \\
\hline 2015 & 1,96 & 2,89 \\
\hline 2016 & 2,67 & 3,56 \\
\hline 2017 & 1,84 & 2,78 \\
\hline 2018 & 1,82 & 2,76 \\
\hline
\end{tabular}

Sumber: Hasil analisis, 2020

* Data Hujan diambil dari STA BMKG Lembang

Setelah diperoleh rumus regresi, kemudian data curah hujan per tahun mulai dari tahun 2015 sebagai nilai X dimasukan ke dalam rumus untuk memperoleh nilai Y yaitu debit. Hasil perhitungan debit dengan menggunakan rumus regresi linear dapat dilihat pada Tabel 1.1. Selain curah hujan, terdapat variabel-variabel lainnya yang juga mempengaruhi debit sungai yaitu guna lahan dan koefisien limpasan. Hubungan antara guna lahan, curah hujan, koefisien limpasan, dan debit dapat dianalisis dengan metode SCS-CN. Tahapan perhitungan dengan metode SCS-CN yang dilakukan yaitu:

1. Menghitung nilai CN (koefisien limpasan) di masing-masing tutupan lahan

2. Menghitung debit dengan nilai $\mathrm{CN}$ yang diperoleh dari tahap 1

3. Melakukan kalibrasi dengan menghitung nilai Nash-Sutcliffe Efficiency (NSE)

Perhitungan debit di Sub DAS Cikapundung-Maribaya dilakukan dengan menggunakan metode SCS-CN. Namun, terlebih dahulu dihitung nilai koefisien CN untuk masing-masing jenis tutupan lahan. Nilai CN ini menurut Chow (1988) terbagi ke dalam 3 (tiga) kondisi yaitu kering, normal, dan basah. Kondisi tersebut ditentukan oleh besarnya hujan harian dibandingkan dengan hujan antecedent moisture conditions (AMC) yang terjadi selama 5 (hari) sebelum hujan harian yang akan dihitung. Kondisi kering ketika nilai AMC berada pada AMC (I), kondisi normal ketika AMC berada pada AMC (II), dan kondisi basah berada pada AMC (III). Sebagai contoh, untuk menentukan hujan pada tanggal 6 tergolong ke dalam AMC golongan berapa, maka terlebih dahulu dijumlahkan hujan pada tanggal 1 hingga tanggal 5. Nilai CN yang akan dihitung dalam penelitian ini diperoleh dari hasil modifikasi berdasarkan beberapa penelitian sebelumnya yaitu penelitian Heriyanto (2018), Laturua et al. (2018), 
Marko \& Zulkarnain (2018), dan Gaghana et al. (2019). Berdasarkan hasil perhitungan, diperoleh nilai CN sebagaimana dapat dilihat pada Tabel 1.12.

Tabel 1.12 Nilai CN Sub DAS Cikapundung-Maribaya Tahun 2009-2018

\begin{tabular}{|c|c|}
\hline Tahun & CN Value \\
\hline 2009 & 57.275 \\
\hline 2010 & 57.275 \\
\hline 2011 & 57.275 \\
\hline 2012 & 57.275 \\
\hline 2013 & 57.275 \\
\hline 2014 & 62.591 \\
\hline 2015 & 62.591 \\
\hline 2016 & 62.591 \\
\hline 2017 & 62.590 \\
\hline 2018 & 62.591 \\
\hline
\end{tabular}

Sumber: Hasil perhitungan, 2020

Tabel 1.13 Guna Lahan Sub DAS Cikapundung-Maribaya Tahun 2009-2018

\begin{tabular}{|l|c|c|c|c|c|c|c|c|c|c|}
\hline \multirow{2}{*}{ Guna Lahan } & \multicolumn{10}{|c|}{ Luas (ha) } \\
\cline { 2 - 12 } & 2009 & 2010 & 2011 & 2012 & 2013 & 2014 & 2015 & 2016 & 2017 & 2018 \\
\hline $\begin{array}{l}\text { Hutan } \\
\text { Tanaman }\end{array}$ & 32,3 & 32,3 & 32,3 & 32,3 & 32,3 & 32,6 & 32,6 & 32,6 & 32,5 & 32,5 \\
\hline $\begin{array}{l}\text { Hutan Lahan } \\
\text { Kering }\end{array}$ & 6,2 & 6,2 & 6,2 & 6,2 & 6,2 & 5,8 & 5,8 & 5,8 & 5,9 & 5,9 \\
\hline $\begin{array}{l}\text { Pertanian } \\
\text { Lahan Kering }\end{array}$ & 0,9 & 0,9 & 0,9 & 0,9 & 0,9 & 26,3 & 26,3 & 26,3 & 26,2 & 26,2 \\
\hline $\begin{array}{l}\text { Pertanian } \\
\text { Lahan Kering } \\
\text { Bercampur }\end{array}$ & 34,0 & 34,0 & 34,0 & 34,0 & 34,0 & 5,1 & 5,1 & 5,1 & 5,1 & 5,1 \\
\hline Pemukiman & 3,6 & 3,6 & 3,6 & 3,6 & 3,6 & 7,1 & 7,1 & 7,1 & 7,2 & 7,2 \\
\hline Total Luas & 77,1 & 77,1 & 77,1 & 77,1 & 77,1 & 77,1 & 77,1 & 77,1 & 77,1 & 77,1 \\
\hline
\end{tabular}

Sumber: Hasil perhitungan, 2020 
IJEEM: Indonesian Journal of Environmental Education and Management

e-ISSN: 2549-5798

Vol.6 No. 2, 31 Juli 2021

DOI : doi.org/10.21009/IJEEM.062.01

Tabel 1.14 Komposisi Guna Lahan Sub DAS Cikapundung-Maribaya Tahun 2009-2018

\begin{tabular}{|l|c|c|c|c|c|c|c|c|c|c|}
\hline \multirow{2}{*}{ Guna Lahan } & \multicolumn{10}{|c|}{ Komposisi Luas (\%) } \\
\cline { 2 - 13 } & 2009 & 2010 & 2011 & 2012 & 2013 & 2014 & 2015 & 2016 & 2017 & 2018 \\
\hline $\begin{array}{l}\text { Hutan } \\
\text { Tanaman }\end{array}$ & 42 & 42 & 42 & 42 & 42 & 42 & 42 & 42 & 42 & 42 \\
\hline $\begin{array}{l}\text { Hutan Lahan } \\
\text { Kering }\end{array}$ & 8 & 8 & 8 & 8 & 8 & 8 & 8 & 8 & 8 & 8 \\
\hline $\begin{array}{l}\text { Pertanian } \\
\text { Lahan Kering }\end{array}$ & 1 & 1 & 1 & 1 & 1 & 34 & 34 & 34 & 34 & 34 \\
\hline $\begin{array}{l}\text { Pertanian } \\
\text { Lahan Kering } \\
\text { Bercampur }\end{array}$ & 44 & 44 & 44 & 44 & 44 & 7 & 7 & 7 & 7 & 7 \\
\hline Pemukiman & 5 & 5 & 5 & 5 & 5 & 9 & 9 & 9 & 9 & 9 \\
\hline Total Luas & 100 & 100 & 100 & 100 & 100 & 100 & 100 & 100 & 100 & 100 \\
\hline
\end{tabular}

Sumber: Hasil perhitungan, 2020

Setelah nilai debit harian diperoleh dari metode SCS-CN menggunakan CN Sub DAS Cikapundung-Maribaya hasil perhitungan, dilakukan kalibrasi dengan menghitung nilai NashSutcliffe Efficiency (NSE). Nilai NSE hasil perhitungan adalah sebesar 61\%. Berdasarkan hasil interpretasi NSE, dengan mengacu pada Tabel 1.1 dapat disimpulkan bahwa data debit harian tahun 2009-2018 dengan menggunakan nilai CN pada Tabel 1.12 berada dalam kategori memenuhi. Artinya, nilai CN dapat digunakan untuk perhitungan nilai debit di Sub DAS Cikapundung-Maribaya. Jika dilihat pada Tabel 1.12, nilai CN menjadi lebih besar pada tahun 2014 yaitu dari 57,275 menjadi 62,591. Artinya koefisien limpasan langsung akibat perubahan tutupan lahan terbangun semakin besar yang menyebabkan air hujan tidak terserap ke dalam tanah namun langsung menjadi debit sungai. Semakin besar tutupan lahan terbangun, akan semakin besar juga limpasan langsung atau debit yang dihasilkan di suatu daerah aliran sungai namun dapat mengancam kondisi debit pada saat musim kering. Hal tersebut disebabkan sedikitnya air yang terserap ke dalam tanah menjadi air tanah dangkal dan mempertahankan besaran baseflow di suatu DAS. Oleh karena itu perlu dijaga luas guna lahan tidak kedap air agar dapat menjaga besaran debit minimun pada probabilitas $99 \%$ untuk memenuhi kebutuhan air bersih Kota Bandung. Luas dan komposisi guna lahan selama 2009-2018 sebagaimana dapat dilihat pada Tabel 1.13 dan Tabel 1.14 adalah kondisi di mana besarnya debit andalan $99 \%$ sebesar $0,76 \mathrm{~m}^{3} /$ detik atau 760 liter/detik sebagaimana dapat dilihat pada Gambar 1.3. Besarnya debit andalan tersebut masih dapat memenuhi kebutuhan air baku PDAM Tirta 
Wening di IPA Dago Pakar sebesar 640 liter/detik meskipun masih di bawah kebutuhan air baku sebesar 840 liter/detik dari debit Sungai Cikapundung. Keandalan tersebut masih terjaga karena komposisi luas hutan selama 2009-2018 dipertahankan sebesar 50\%. Untuk dapat tetap memenuhi kebutuhan air baku di IPA Dago Pakar beberapa tahun mendatang, komposisi luas hutan harus dijaga minimal 50\% atau ditingkatkan di atas 50\% agar dapat meningkatkan keandalan debit.

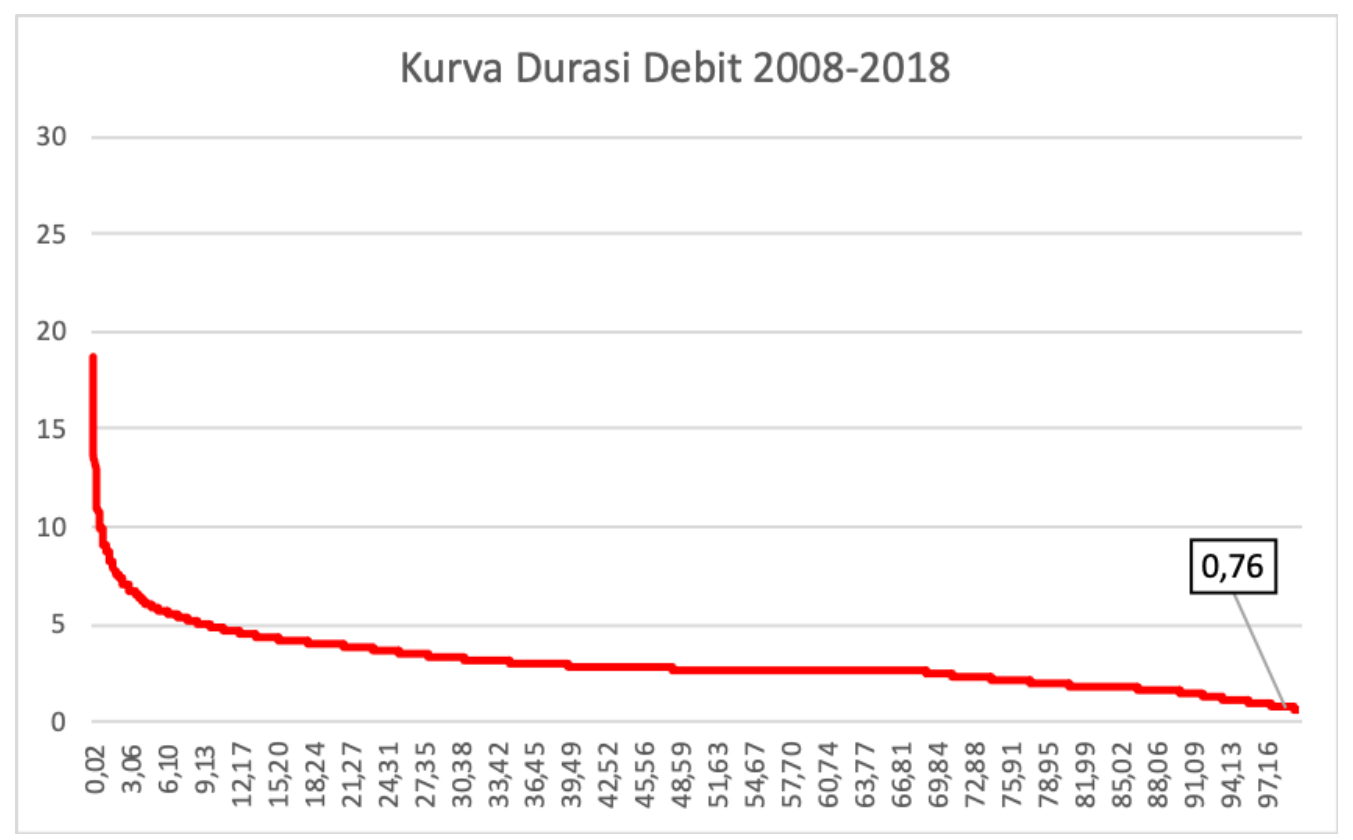

Gambar 1.3 Kurva Durasi Debit Sungai Cikapundung 2008-2018

\section{KESIMPULAN}

Perubahan tata guna lahan di DAS Cikapundung, yaitu perubahan lahan hutan menjadi lahan terbangun, memberikan dampak pada kuantitas air sungai yaitu infiltrasi tanah yang sangat minim dan berakibat pada tidak adanya air tanah yang menyebabkan berkurangnya aliran dasar (baseflow) sungai pada musim kering Berdasarkan hasil perhitungan, diperoleh nilai CN berubah pada tahun 2014 yaitu dari 57,275 menjadi 62,591 di mana mulai terjadi perubahan tutupan lahan. Semakin besar tutupan lahan terbangun, akan semakin besar juga limpasan langsung atau debit yang dihasilkan di suatu daerah aliran sungai namun dapat mengancam kondisi debit pada saat musim kering. Hal tersebut disebabkan sedikitnya air yang 
terserap ke dalam tanah menjadi air tanah dangkal dan mempertahankan besaran baseflow di suatu DAS. Perubahan tutupan di Sub DAS Cikapundung-Maribaya yang menjadi hulu DAS Cikapundung tersebut harus dikendalikan agar dapat menjaga keseimbangan siklus hidrologi di DAS Cikapundung. Untuk dapat tetap memenuhi kebutuhan air baku di IPA Dago Pakar beberapa tahun mendatang, komposisi luas hutan harus dijaga minimal 50\% atau ditingkatkan di atas 50\% agar dapat meningkatkan keandalan debit.

\section{DAFTAR PUSTAKA}

Ante, E., Benu, N. M., Moniaga, V. R. B. (2016). Dampak Ekonomi dan Sosial Alih Fungsi Lahan Pertanian Hortikultura menjadi Kawasan Wisata Bukit Rurukan di Kecamatan Tomohon Timur, Kota Tomohon. Agri-SosioEkonomi Unsrat, Vol. 12, 113-124, (No. 3).

Darul, A., Irawan, D. E., Trilaksono, N. J., Pratama, A., \& Fitria, U. R. (2016). Conceptual model of groundwater and river water interactions in Cikapundung riverbank, Bandung, West Java. In IOP Conference Series: Earth and Environmental Science (Vol. 29, No. 1, p. 012026). IOP Publishing.

Fadhli, R. A., Sujatmoko, B., \& Sutikno, S. (2015). Perbandingan Pengunaan Data Hujan Lapangan dan Data Hujan Satelit untuk Analisis Aliran Menggunakan Model IHACRES. Jom FTEKNIK, Vol. 2.

Gaghana, M. I. S., Binilang, A., \& Hendratta, L. A. (2019). Analisis Kapasitas Penampang Sungai di Kelurahan Tona 1 Kabupaten Sangihe. Jurnal Sipil Statik, Vol. 7, 449462, (4).

Heriyanto, A. (2018). Studi Pengaruh Perubahan Tata Guna Lahan DAS Ciujung Bagian Hulu Terhadap Debit di Sungai Ciujung. Surabaya: Institut Teknologi Sepuluh Nopember.

Laturua, A., Hendrayanto, \& Puspaningsih, N. (2018). Penggunaan Lahan Optimal Dalam Transformasi Hujan Limpasa di DAS Wae Ruhu. Media Konservasi, Vol. 23, 52$64,(1)$.

Kuntoro, A. A., Irawan, D. E., Darul, A., Sumadi, H., Argo, T. A., \& Nurhayati, Y. (2017). Beban ganda pengelolaan air tanah di kabupaten/kota pasca pembatalan UU No 7/2004 tentang Sumber Daya Air: Ilustrasi dari Kota Bandung. Jurnal Ilmu Sosial dan Humaniora, 6(1), 83-96.

Marbun, F., Suganda, B. R., Iskandarsyah, T. Y. W., Barkah, M. N., Setiawan, T., \& Hadian, M. S. D. (2018). Potensi Air Tanah Berdasarkan Neraca Air Pada Daerah Aliran 
IJEEM: Indonesian Journal of Environmental Education and Management e-ISSN: 2549-5798

Vol.6 No. 2, 31 Juli 2021

DOI : doi.org/10.21009/IJEEM.062.01

Sungai Cikapundung Wilayah Cekungan Bandung, Jawa Barat. Geoscience Journal, 2(4), 294-301.

Maria, R. (2008). Studi Laju Deoksigenasi pada Sungai Cikapundung untuk Ruas Siliwangi Asia Afrika, Bandung. Jurnal Riset Geologi dan Pembangunan, Jilid 18, 21-30, (No.2).

Marko, K. \& Zulkarnain, F. (2018). Pemodelan debit banjir sehubungan dengan prediksi perubahan tutupan lahan di daerah aliran Ci Leungsi Hulu menggunakan HECHMS. JGLITrop, Vol. 2, 26-37, (1).

Raksanagara, A. S., Santanu, A. M., Sari, S. Y. I., Sunjaya, D. K., Arya, I. F. D., Agustian, D. (2017). Faktor yang Memengaruhi Perilaku Penggunaan Air Bersih pada Masyarakat Kumuh Perkotaan berdasar atas Integrated Behavior Model. MKB, Vol. 49, 122-131, (No. 2).

Ramelan, R. (2004). Kajian Pengelolaan Sumber Air Baku di Kota Bandung dan Kabupaten Bandung. Semarang: Universitas Diponegoro. 